\title{
Hormonal and Cardiovascular Reflex Assessment in a Female Patient with Pure Autonomic Failure
}

\author{
Heno Ferreira Lopes, Fernanda Marciano Consolim-Colombo, Denise Hachul, \\ Maria Elisa do A maral Carvalho, Fúlvio Pileggi, Hélio Bernardes Silva
}

São Paulo, SP - Brazil

\begin{abstract}
We report the case of a 72-year-old female with pure autonomic failure, a rare entity, whose diagnosis of autonomic dysfunction was determined with a series of complementary tests. For approximately 2 years, the patient has been experiencing dizziness and a tendency to fall, a significant weight loss, generalized weakness, dysphagia, intestinal constipation, blurred vision, dry mouth, and changes in her voice. She underwent clinical assessment and laboratory tests (biochemical tests, chest $X$-ray, digestive endoscopy, colonoscopy, chest computed tomography, abdomen and pelvis computed tomography, abdominal ultrasound, and ambulatory blood pressure monitoring). Measurements of catecholamine and plasmatic renin activity were performed at rest and after physical exercise. Finally the patient underwent physiological and pharmacological autonomic tests that better diagnosed dysautonomia.
\end{abstract}

Reflex regulation of blood pressure at each moment is extremely important for the adaptation of the individual to different daily situations. Postural and emotional changes, and physical activity depend on a precise and rapid regulation of blood pressure. The central nervous system and autonomic nervous system are fundamental components of reflex regulation of blood pressure. The integrity of these systems along with the normal function of effector organs constitute important and fundamental mechanisms for maintaining a normal range of blood pressure at rest and during physical or mental activity. The autonomic nervous system consists of the sympathetic and parasympathetic systems that comprise afferent and efferent fibers interacting with neurohormones (noradrenaline and acetylcholine) to form the reflexes of cardiovascular adaptation ${ }^{1}$, mainly the bradycardia and tachycardia reflexes modulated through baroreceptors. Another important reflex in the adaptation to variations in posture and blood volume is the cardiopulmonary reflex. Functioning of arterial baroreflexes and cardiopulmonary reflex depend on sensors (receptors) to varia-

Instituto do Coração do Hospital das Clínicas - FMUSP

Mailing address: Heno Ferreira Lopes - InCor - Unidade de Hipertensão - Av. Dr

Enéas C. Aguiar, 44 - 05403-000 - São Paulo, SP - Brazil

English version by Syela Maris C. Gandour tions in pressure and volume. These receptors are located in the cardiovascular system (ventricles, atria, aortic arch, pulmonary trunk, and carotid sinus). The sensitivity of these receptors and integrity of the afferent and efferent vias as a whole are very important for the functioning of the cardiopulmonary reflex and arterial baroreflexes (bradycardia and tachycardia) in humans and animals ${ }^{2-5}$. The aging process, as well as some diseases affecting human being, may impair the functioning of cardiovascular reflexes. Of the diseases that may evolve with changes in the regulation of cardiovascular reflexes and pressoreceptor sensitivity, we may emphasize diabetes, heart failure, chronic renal failure, arterial hypertension, Chagas' disease, Parkinson's disease, amyloidosis, and other storage diseases ${ }^{6}$. Some diseases interfere with reflex integration because they impair several areas of the autonomic nervous system directly related to reflexes. Pure autonomic failure or idiopathic orthostatic hypotension, which is a neurogenic form of orthostatic hypotension, deserves special mention. This is a disease of unknown etiology, whose clinical findings are characterized by symptoms related to dysautonomia, mainly dizziness and postural hypotension. We report the clinical and hormonal findings and the changes in the cardiovascular reflexes in a female with pure autonomic failure.

\section{Case Report}

The patient is a 72-year-old female complaining of dizziness and the tendency to fall during the last 2 years. The symptoms of dizziness improved when the patient sat or assumed a horizontal position. She reported a substantial weight loss during that period ( $25 \mathrm{~kg}$ in 2 years) and generalized weakness, especially in the upper and lower limbs. Her appetite was normal, but she had difficulty in swallowing dry food, preferring a soft diet. She also reported intestinal constipation, blurred vision, dry mouth, and changes in her voice (husky voice).

On physical examination, the patient was hydrated, acyanotic, anicteric, with a dry oral mucosa. The lungs showed no rales and the heart rhythm was regular with no murmurs. Her heart rate was $80 \mathrm{bpm}$, and it did not change from the sitting to the orthostatic position. Her blood pressure was $140 / 90 \mathrm{mmHg}$ (in the horizontal position), $80 / 50 \mathrm{mmHg}$ 
(sitting), and 60/40mmHg (upright posture) in both upper limbs. Her abdominal examination was normal. The following additional tests were normal: hemogram, biochemistry, and urinary sediment. Results of the following procedures were also normal: chest X-ray, digestive endoscopy, colonoscopy, chest computed tomography, abdomen and pelvis computed tomography, and abdominal ultrasound. Ambulatory blood pressure monitoring showed a mean systolic blood pressure of $143 \mathrm{mmHg}$, a mean diastolic blood pressure of $81 \mathrm{mmHg}$, and a mean blood pressure of $103 \mathrm{mmHg}$ in 24 hours. The blood pressure curve followed the circadian pattern, but significant drops in pressure occurred when the patient took the orthostatic posture (fig. 1). Her heart rate changed very little during the entire period of examination. In addition to the already mentioned tests, measurement of the plasmatic renin activity at rest was performed, and it was $0.56 \mathrm{ng} / \mathrm{mL} / \mathrm{h}$ (normal value for the patient's condition ranges from 1.44 to $2.80 \mathrm{ng} / \mathrm{mL} / \mathrm{h}$ ). After physical exercise, plasmatic renin activity was $0.23 \mathrm{ng} / \mathrm{mL} /$ $\mathrm{h}$. Levels of noradrenaline, adrenaline, and dopamine were, respectively, $95.5 \mathrm{pg} / \mathrm{mL}$, undetectable, and $32.4 \mathrm{pg} / \mathrm{mL}$. After physical exercise (walking), the values of noradrenaline, adrenaline, and dopamine were $54.4 \mathrm{pg} / \mathrm{mL}, 6.3 \mathrm{pg} / \mathrm{mL}$, and $10 \mathrm{pg} / \mathrm{mL}$, respectively.

The cold pressure test was performed according to the pattern used in our laboratory (Hines and Brown technique). It consisted of immersing one hand (to the wrist) of the patient in ice cold water (approximately $4^{\circ} \mathrm{C}$ ) for 60 seconds ${ }^{7}$. Blood pressure and heart rate did not change during the test.

The hand-grip test was performed according to a technique established in our laboratory. This test consists of applying to the patient's right upper limb an effort equivalent to $40 \%$ of the patient's total force for 90 seconds in a dynamometer. Blood pressure and heart rate did not change during the isometric effort.

The patient exerted an expiratory effort equivalent to a pressure of $40 \mathrm{mmHg}$ for 20 seconds through a tube connected to a mercury manometer, and the patient's response to the Valsalva maneuver was atypical, showing a progressive drop in the arterial pressure during the forced expiratory

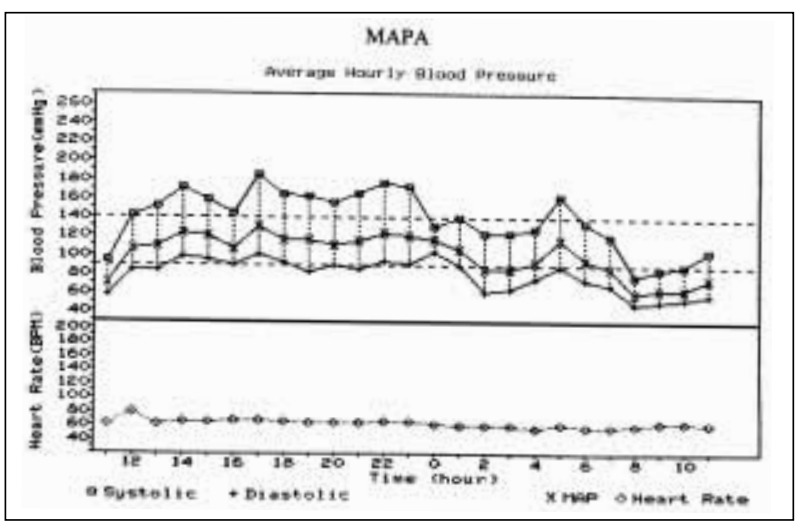

Fig. 1 - Ambulatory blood pressure monitoring - mean values of blood pressure and heart rate in 24 hours. Blood pressure significantly decreases when the patient takes the orthostatic position (from 6 to 10 hours). effort until phase III. The patient recovered during phase IV, but showed no elevation during this phase. Her heart rate did not change during the maneuver (fig. 2).

The tilt test showed a drop of $65 \mathrm{mmHg}$ in systolic arterial pressure and of $20 \mathrm{mmHg}$ in diastolic arterial pressure at the initial minute of $60^{\circ}$ inclination, and it was maintained during the entire period of inclination (20 minutes). Her heart rate did not change during this period (fig. 3). Basal plasmatic renin activity was $0.56 \mathrm{ng} / \mathrm{mL} / \mathrm{h}$ and after passive orthostatic inclination it was $0.9 \mathrm{ng} / \mathrm{mL} / \mathrm{h}$, i.e., plasmatic renin activity basically did not change. Noradrenaline and dopamine values at the basal level were 95.5 and $32.4 \mathrm{pg} / \mathrm{mL}$, respectively, and after inclination, the values changed to 69.2 and $25.3 \mathrm{pg} / \mathrm{mL}$, respectively. Basal noradrenaline was undetectable and increased to $46.7 \mathrm{pg} / \mathrm{mL}$ after the test. The patient reported no symptoms during passive postural inclination.

The bradycardia and tachycardia reflexes were assessed in this patient according to the technique established and used in our laboratory in previous studies ${ }^{8-10}$. This consisted of injection of drugs with vasoconstrictive and vasodilating properties in bolus. The bradycardia reflex was assessed through intravenous injection of $100 \mu \mathrm{g}$ of phenylephrine in bolus. The patient responded with de-

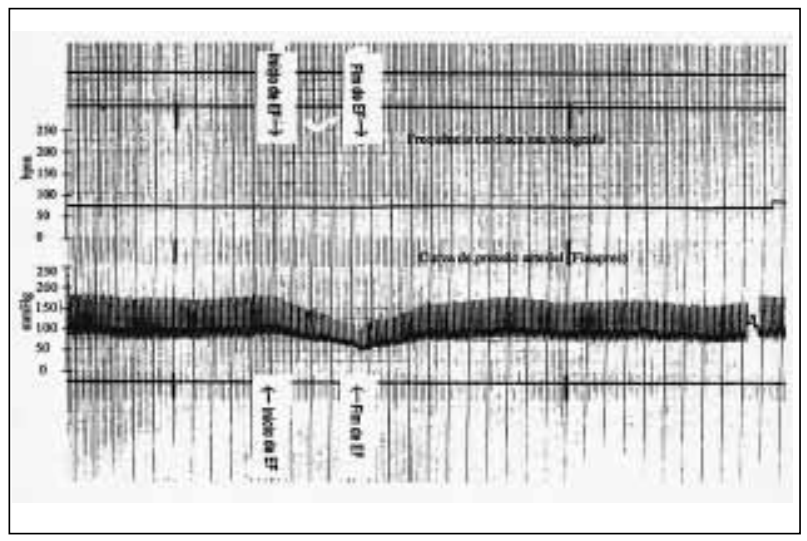

Fig. 2 - Valsalva maneuver - The different phases of the maneuver are not shown Blood pressure progressively decreased at the beginning of the expiratory effort (EF), and it slowly recovered after interruption of the effort.

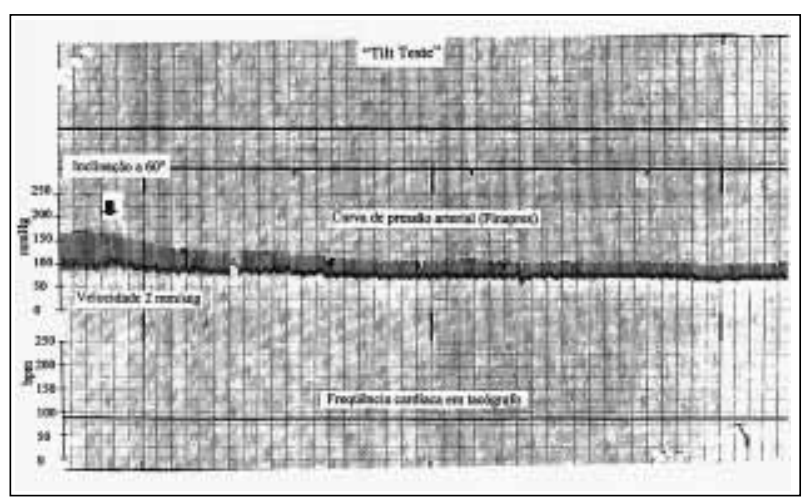

Fig. 3 - Tilt test-Blood pressure curve beat-to-beat (Finapres) and heart rate at tachograph with a $60^{\circ}$ inclination. Significant drop in blood pressure with no change in heart rate. 
pressed bradycardia (fig. 4). The index found was $0.06 \mathrm{~ms} /$ $\mathrm{mm} \mathrm{Hg}$. The tachycardia reflex was evaluated through intravenous injection of $100 \mu \mathrm{g}$ of nitroglycerin in bolus. The index found was $0.08 \mathrm{~ms} / \mathrm{mmHg}$. The indices found in the evaluation of sensitivity of the pressoreceptors for the bradycardia and tachycardia reflexes corresponded to the inclination of the straight line resulting from the linear regression of the variation in the systolic arterial pressure $(\mathrm{mmHg})$ and the variation in the RR interval ( $\mathrm{ms}$ ) caused by the drug bolus (Oxford method).

Pharmacological tests with isoprenaline and atropine were performed to assess the response of cardiac beta-adrenergic receptors and the cardiac sympathetic response after vagal block with atropine.

Administration of $0.2 \mathrm{mcg} / \mathrm{min}$ of isoprenaline caused an increase of $35 \mathrm{bpm}$ in heart rate, a decrease in the systolic arterial pressure of $65 \mathrm{mmHg}$ and in the diastolic arterial pressure of $33 \mathrm{mmHg}$ (fig. 5). Injection of atropine at the dosage of $0.04 \mathrm{mg} / \mathrm{kg}$ of weight caused an increase of $7 \mathrm{bpm}$ in the patient's heart rate.

Blood pressure during the autonomic tests was measured beat per beat with a Finapres (Ohmeda 2300), and the heart rate was recorded on the electrocardiogram. Both signals of the blood pressure and heart rate were recorded on a 4-channel polygraph (Hewlett-Packard 7700).

\section{Discussion}

The clinical case reported is a classical example of pure autonomic failure, a form of neurogenic hypotension of slow and insidious evolution. The symptoms of dizziness and the tendency to fall that improve when the patient sits or lies down, dry mouth, and intestinal constipation reported by the patient are relatively frequent in individuals with this type of autonomic disorder ${ }^{11}$. Decreases in blood pressure and absence of changes in heart rate with a change in posture observed on physical examination and recorded in the ambulatory blood pressure monitoring reflect an autonomic denervation in the patient, characterizing a typical

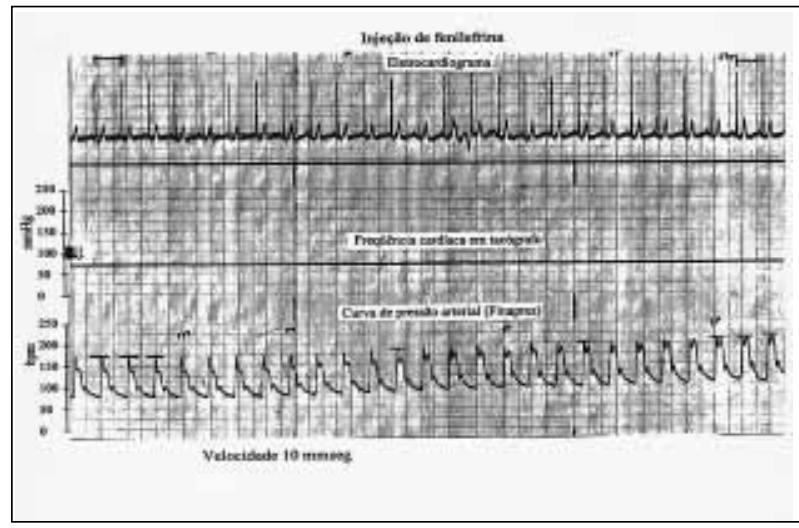

Fig. 4-Bradycardia reflex - Blood pressure curve beat-to-beat (Finapres) and heart rate on electrocardiogram and tachograph during bolus injection of phenylephrine. Significant increase in blood pressure occurs and heart rate remains unchanged.

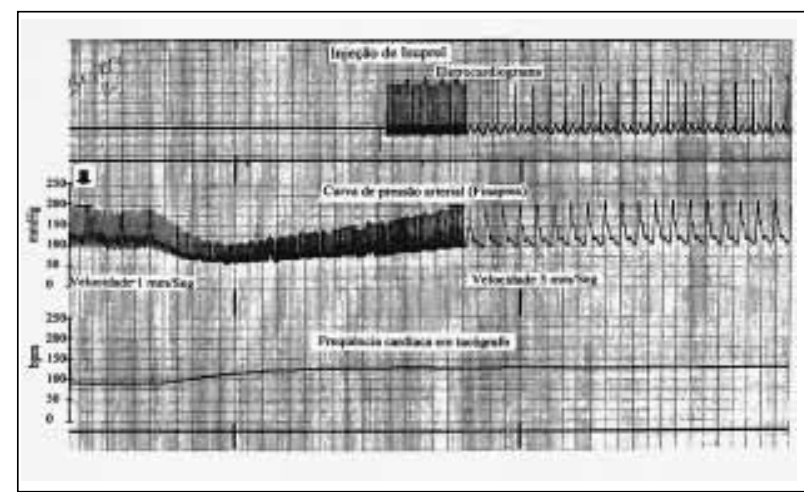

Fig. 5 - Isoprenaline injection - Blood pressure curve beat-to-beat (Finapres) and heart rate on electrocardiogram and tachograph during intravenous isoprenaline injection. A significant drop in blood pressure and an increase in heart rate occurred after isoprenaline injection.

picture of orthostatic intolerance. Neurohormonal control of the cardiovascular reflexes is directly related to the autonomic nervous system. Noradrenaline is the major neurohormone in this system (sympathetic nervous system), and it interacts with the renin-angiotensin system modulating renin production ${ }^{12}$. Our patient had plasmatic renin activity and the plasmatic level of catecholamines depressed at rest, and they remained depressed after physical exercise and the tilt test. This response is characteristic of individuals with this form of autonomic failure, reflecting the absence of response of the sympathetic nerve fibers in the synaptic cleft (noradrenaline production), in the juxtaglomerular cells of the kidneys (renin production), and in the medulla of the adrenal gland (adrenaline production). Blood pressure and heart rate did not change during the cold pressure test. In healthy individuals, the response to the cold pressure test is characterized by an increase in systolic and diastolic blood pressures, increase in heart rate due to an increase in the sympathetic activity, which may be mild in normotensive individuals and exacerbated in hypertensive patients ${ }^{7}$. Absence of pressure response and of heart rate change in our patient reflects absence of peripheral sympathetic activity. During isometric effort (hand-grip test), the patient did not experience elevation in pressure levels and heart rate, which were expected responses during this maneuver due to the release of catecholamines. This test, therefore, also reflects the absence of sympathetic response in our patient. Valsalva maneuver in healthy individuals is characterized by 4 distinct phases as follows: phase I - characterized by an increase in systolic and diastolic pressures and decrease in heart rate during deep inspiration; phase II - characterized by a decrease in blood pressure and tachycardia during forced expiration; phase III - characterized by a sudden decrease in blood pressure at the time of interruption of the forced expiratory effort; phase IV - occurs after interruption of the forced expiratory effort and is characterized by a significant increase in blood pressure (overshoot) and intense bradycardia. In the Valsalva maneuver, our patient had a decrease of $75 \mathrm{mmHg}$ in systolic blood pressure at the end of the forced expiration (phase II), and no increase in heart rate occurred as expected. In phase IV, slow elevation in 
blood pressure occurred without overshoot and bradycardia. These alterations in the Valsalva maneuver suggest sympathetic denervation in the patient. During the tilt test, a decrease of $60 \mathrm{mmHg}$ in systolic pressure and of $20 \mathrm{~m}$ $\mathrm{mHg}$ in diastolic pressure occurred and heart rate did not change. Plasmatic renin activity (before the tilt test: 0.56 ; after: $0.9 \mathrm{ng} / \mathrm{mL} / \mathrm{h}$ ) noradrenaline (before: 95.5 ; after: $69.2 \mathrm{pg}$ / $\mathrm{mL}$ ), and dopamine (before: 32.4 ; after: $25.3 \mathrm{pg} / \mathrm{mL}$ ) levels remained depressed after postural inclination. Adrenaline, which was undetectable in the supine position, increased to $46.7 \mathrm{pg} / \mathrm{mL}$ after postural inclination, but this level is considered depressed for this condition, reflecting absence of sympathetic activity, which in normal conditions increases after passive orthostatic inclination ${ }^{4}$. In regard to the pharmacological tests with phenylephrine and nitroglycerin, the bradycardia and tachycardia reflexes were depressed, reflecting an impairment of at least part of the system integrating the reflexes mediated by baroreceptors (afferent via, vasomotor center, efferent via, effector organ $=$ heart). In regard to the test with isoprenaline, the patient had a decrease of $65 \mathrm{mmHg}$ in systolic pressure, of $33 \mathrm{mmHg}$ in diastolic pressure, and an increase of $35 \mathrm{bpm}$ in heart rate. This response to isoprenaline that is a beta-agonist made us believe that the effector organ (heart) and its adrenergic receptors were normal and that the depressed response to phenylephrine and nitroglycerin reflected an impairment of other components of the autonomic nervous system involved in the reflexes, such as the afferent and efferent vias, and the vasomotor center. The patient's blood pressure response to the injection of isoprenaline (beta-agonist) and phenyle- phrine (alpha-agonist) was exacerbated, suggesting a hypersensitivity of adrenergic receptors. The atropine test showed a depressed chronotropic response of the heart (increase of $5 \mathrm{bpm}$ in heart rate). The altered response to atropine stresses the hypothesis of impairment of the sympathetic nervous system in our patient.

To summarize, we used different tests to assess our patient aiming to characterize and document both the sympathetic and parasympathetic impairment of the autonomic nervous system in pure autonomic failure. The cold pressure test allowed evaluation of the sympathetic component. The different phases of the Valsalva maneuver gave us an idea of how the cardiopulmonary and arterial baroreflexes were functioning. The tilt test also gave us an idea of how cardiopulmonary baroreceptors related to peripheral sympathetic response worked. Aldosterone level and plasmatic renin activity along with plasmatic levels of catecholamines after postural inclination gave us an idea of the functioning of the sympathetic nervous system and the renin-angiotensin system, which was somehow directly related to the sympathetic nervous system. The tachycardia reflex depended on the sensitivity of the baroreceptors, integrity of the vasomotor center, more precisely the nucleus of the solitary tract, efferent nervous fibers, and cardiac adrenergic receptors. The bradycardia reflex also depended on the sensitivity of baroreceptors, vasomotor center, and vagal efferent fibers. Therefore, this set of tests analysed as a whole allowed us to characterize impairment of the autonomic nervous system in pure autonomic failure, which is a true challenge for physicians.

\section{References}

1. Salata JJ, Zipes DP. Autonomic nervous system control of heart rate and atrioventricular nodal conduction. In: Zucker IH, Gilmore JP, eds. Reflex Control of the Circulation, $1^{\text {st }}$ edition. Florida: Boca Raton, CRC Press, 1991.

2. Smith JJ, Ebert J. General response to orthostatic stress. In: Smith JJ. (ed.). Circulatory Response to the Upright Posture. Florida: Boca Raton, CRC Press, 1990: 1-46

3. Cowley AW. Long-term control of arterial pressure. Physiol Ver 1992; 72: 23178.

4. Zoller RP, Mark AL, Abboud FM, Schmid PG, Heistad DD. The role of low pressure baroreceptors in reflex vasoconstrictor responses in man. J Clin Invest 1972; 51: 2967-72.

5. Mancia G, Mark Al. Arterial baroreflexes in humans. In: Shepherd JT, Abboud FM. (eds.), Handbook of Physiology. Section 2: The Cardiovascular System. Volume III. Maryland: American Physiological Society, 1983: 755-93.

6. Robertson D. Clinical evaluation of autonomic function. In: Robertson, Low and Polinsky, eds. Primer on the Autonomic Nervous System, $1^{\text {st }}$ edition. San Diego: Academic Press, 1996

7. Hines EA, Brown GE. The cold pressure test for measuring the reactibility of the blood pressure: data concerning 571 normal and hypertensive subjects. Am Heart J 1936; 11: 1-9.

8. Bortolotto LA. Estudo do controle autonômico da pressão arterial e da freqüência cardíaca na hipertensão arterial após transplante cardíaco. Tese de Doutorado - Faculdade de Medicina, USP. São Paulo, 1996: 143p.

9. Giorgi DMA, Lopes HF, Bernardes Silva H, Krieger EM. Alterations in the autonomic nervous system in Chagas' disease associated with hypertension. In: Inter-American Society of Hypertension. Montreal: Abstract Book, 1995: 11.

10. Lopes HF. Avaliação do comportamento da pressão arterial, frequiência cardíaca, reflexos cardiovasculares e do metabolismo lipídico em jovens filhos de hipertensos. Tese de Doutorado - Faculdade de Medicina - USP. São Paulo, 1998: $123 \mathrm{p}$.

11. Schatz IJ. Pure Autonomic Failure. In: Robertson, Low and Polinsky, eds. Primer on the Autonomic Nervous System, $1^{\text {st }}$ edition. San Diego: Academic Press, 1996.

12. Kotchen TA, Hartley LH, Rice TW, Mougey EH, Jones LG, Masow JW. Renin, norepinephrine, and epinephrine responses to graded exercise. J Appl Physiol 1971; 31: 178-84. 